\title{
Sistem Monitoring Dan Pengendalian Data Suhu Ruang Navigasi Jarak Jauh Menggunakan WEMOS D1 Mini
}

\author{
H. Heru Abrianto ${ }^{1 *}$, Kumala Sari ${ }^{2}$ dan Irmayani ${ }^{2}$ \\ ${ }^{1}$ Universitas Tama Jagakarsa \\ Alamat Letjen TB Simatupang No. 152, Jakarta 12530 \\ 2 institut Sains dan Teknologi Nasional \\ Alamat Jl. Moh. Kahfi II, Srengseng Sawah. Jakarta 12640 \\ heruab@jagakarsa.ac.id
}

\begin{abstract}
Abstrak - Ruang perangkat sangat rentan akan munculnya panas, karena perangkat tersebut dijalankan setiap saat. Oleh sebab itu sangat dibutuhkan pendingin ruangan seperti Air Conditioner (AC) pada setiap ruang perangkat agar suhu ruangan selalu dingin sesuai ketentuan yang berlaku karena kondisi suhu ruangan sangat berpengaruh terhadap perangkat. Dari kasus tersebut maka demi memudahkan petugas dalam memantau suhu ruangan perangkat maka dibuat pendeteksi suhu ruangan agar suhu ruangan tidak melewati batas maksimal dan alat tersebut akan memberikan notifikasi secara otomatis langsung ke petugas melalui aplikasi Bylnk pada smartphone. Sebagai penanggulangan atau tindakan pertama di ruang perangkat tersebut maka melalui aplikasi Bylnk pada smartphone petugas dapat menyalakan AC cadangan yang ada pada di ruang perangkat. Prototype alat ini terdiri dari Wemos D1, sensor suhu DHT22, dan switch untuk menyalakan / mematikan AC . Pada pengujian dan sensor suhu DHT22 maemiliki ketidaklinieran terhadap Thermo-Hygrometer ruangan yaitu sebesar $5 \%$ dan selisih nilai pengukuran analog dan digital $1.7^{\circ} \mathrm{C}$. Alat ini dapat mengirimkan notifikasi secara otomatis melalui aplikasi bylnk pada smartphone ketika suhu ruangan melewati batas maksimal, dan aplikasi bylnk pada smartphone juga dapat menyalakan AC cadangan yang terdapat pada ruang perangkat.

Kata kunci: Wemos D1, Smartphone, DHT22, Switch Driver, Notifikasi
\end{abstract}

\section{Pendahuluan}

Perkembangan teknologi ilmu kendali sangat cepat pada dekade ini seiring perkembangan komponen semikondukror yang digunakan untuk sistem keamanan[1]. Berbagai macam penelitian telah dilakukan untuk membantu pekerjaan manusia, diantaranya adalah konsep Internet of things[2][3][4][5].

Ruangan perangkat navigasi sangat rentan akan munculnya panas pada alat tersebut. Apabila perangkat menghasilkan panas yang berlebihan maka akan menyebabkan terbakar dan kerusakan pada perangkat, oleh sebab itu sangat diperlukan pendingin ruangan seperti Air Conditioner (AC) pada setiap ruangan perangkat yang perlu selalu di lakukan pengecekan apakah suhu dalam ruangan tersebut dalam keadaan baik atau buruk. Ruangan perangkat yang pada umumnya tidak memiliki system pendeteksi suhu otomatis di setiap ruang perangkat, namun hanya terdapat sebuah termometer untuk melihat suhu di ruangaan. Batas maskimal suhu ruangan perangkat pada umumnua adalah $22^{\circ} \mathrm{C}$.

Dari kasus tersebut maka demi memudahkan petugas dalam memantau suhu ruangan navigasi agar menghindari kenaikan suhu ruangan melebihi batas maksimal maka perlunya Monitoring dan pengendalian suhu dan sistem pengirim informasi suhu pada ruang navigasi jarak jauh[1][6]. Apabila suhu ruangan melebihi maksimal maka dari alat sensor suhu tersebut akan mengirimkan informasi langsung ke petugas melalui aplikasi bylnk di Smartphone petugas, sehingga AC cadangan pada ruang perangkat dapat dinyalakan dengan menggunakan aplikasi bylnk tersebut yang sudah ditanamkan pada setiap smartphone petugas.

\section{Tinjauan Pustaka}

\subsection{WEMOS D1 MINI BOARD}

Dunia IT khususnya dalam bidang IOT (Internet of Things) atau yang biasa dikenal dalam istilah embedded system sudah semakin pesat. Teknologi ini merupakan suatu bentuk kerja sama antara sistem dengan sistem, untuk membantu pekerjaan manusia di zaman yang semakin canggih ini. Dan salah satu contoh dari pengembangan IOT adalah Wemos D1 mini. Wemos D1 mini merupakan board wifi mini berbasis ESP266 yang dikenal ekonomis dan handal. ESP8266 ini yang bisa menghubungkan perangkat microcontroller seperti arduino dengan internet via wifi. Wemos D1 mini ini dapat membuat project mini tanpa menggunakan arduino sebagai mikrokontrolernya, karena modul Wemos D1 mini dapat bekerja sendiri atau stand-alone untuk memproses setiap bait code atau coding yang masuk.

Pada masa sekarang atau masa yang akan datang, penggunaan komputer akan mendominasi pekerjaan 
manusia atau bahkan akan mengalahkan kemampuan komputasi manusia seperti mengontrol peralatan elektronik dari jarak jauh dengan menggunakan dukungan media IOT (Internet of Things)[7]. Salah satu hardware dari pengembangan yang berbasis IOT adalah Wemos D1 mini, yang merupakan sebuah mikrokontroler hasil pengembangan berbasis modul ESP8266. Masih terdapat modul wifi yang berbasis ESP8266 seperti Nodemcu yang sering digunakan sebagai penghubung internet antara Arduino ke smartphone atau PC melalui jaringan wifi [2][8]. Modul Wemos D1 ini diciptakan sebagai solusi dari mahalnya sebuah modul wireless yang berbasis mikrokontroler[4][9][10]. Dengan adanya mikrokontroler Wemos ini biaya yang dikeluarkan untuk menciptakan sebuah project yang berbasis IOT (Internet Of Things) jadi lebih sedikit, terlebih lagi wemos ini dapat menjalankan sistem kode bait tanpa menggunakan arduino sebagai mikrokontrolernya. Adapun keunggulan menggunakan modul Wemos adalah dapat diprogram menggunakan Arduino IDE dengan sintaks program library yang banyak terdapat di internet dan pin out yang compatible dengan Arduino Uno sehingga mudah untuk menghubungkan dengan arduino shield lainnya serta mempunyai memory yang sangat besar yaitu 4MB. Wemos juga sesuai dengan beberapa bahasa pemograman lainnya seperi bahasa Pyhton dan Lua sehingga memudahkan untuk mengupload program kedalam wemos apabila seorang programmer belum terlalu paham dengan cara program menggunakan Arduino IDE. Bentuk board yang kecil dan harga yang ekonomis membuat banyak pengembang semakin dipermudah untuk menerapkan sebuah perangkat atau project IOT ke dalam Wemos yang akan dikontrol maupun dimonitor menggunakan smartphone atau PC secara online dan realtime. Secara kinerja dan spesifikasi wemos D1 mini ini lebih baik jika dibandingkan dengan Arduino dikarenakan speed dari controller yang lebih baru dan lebih tinggi ditambah telah terintegrasi dengan Wifi connection sehingga dapat update Software via On the Air.

Wemos merupakan salah satu modul board yang dapat berfungsi dengan arduino khususnya untuk project yang mengusung konsep IOT. Wemos dapat running stand-alone tanpa perlu dihubungkan dengan mikrokontroler, berbeda dengan modul wifi lain yang masih membutuhkan mikrokontroler sebagai pengrontrol atau otak dari rangkaian tersebut, wemos dapat running stand-alone karena didalammnya sudah terdapat CPU yang dapat memprogram melalui serial port atau via OTA serta transfer program secara wireless.

Wemos memiliki 2 buah chipset yang digunakan sebagai otak kerja antara lain.

a. Chipset ESP8266

ESP8266 merupakan sebuah chip yang memiliki fitur Wifi dan mendukung stack TCP/IP. Modul kecil ini memungkinkan sebuah mikrokontroler terhubung kedalam jaringan Wifi dan membuat koneksi TCP/IP hanya dengan menggunakan command yang sederhana. Dengan clock $80 \mathrm{MHz}$ chip ini dibekali dengan 4MB eksternal RAM serta mendukung format IEEE $802.11 \mathrm{~b} / \mathrm{g} / \mathrm{n}$ sehingga tidak menyebabkan gangguan bagi yang lain.

b. Chipset $\mathrm{CH} 340$

CH340 adalah chipset yang mengubah USB serial menjadi serial interface, contohnya adalah aplikasi converter to IrDA atau aplikasi USB converter to Printer. Dalam mode serial interface, CH340 mengirimkan sinyal penghubung yang umum digunakan pada modem. CH340 digunakan untuk mengubah perangkat serial interface umum untuk berhubungan dengan bus USB secara langsung.

\subsubsection{PIN Wemos}

Dalam modul wemos terdapat pin digital dan analog:

a. Pin Digital

Salah satu I/O port pada modul wemos dikenal dengan pin Digital. Pin ini dapat dikonfigurasikan baik sebagai input ataupun output.

b. Pin Analog

Pin analog pada modul wemos ini memiliki 10 bit resolusi dengan nilai maksimal 3.2 Volt. Pin analog ini dapat digunakan persis dengan cara yang sama dengan pin digital.

Gambar 1 memperlihatkan dari Pin Wemos: 


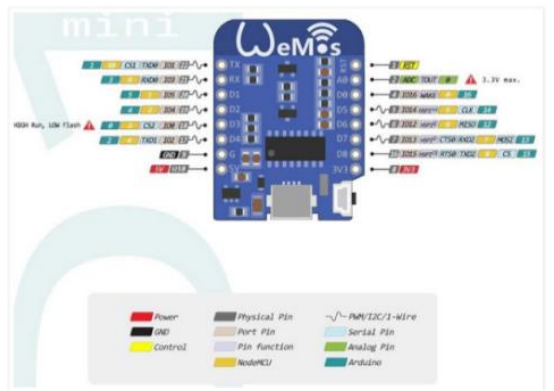

Gambar 1. Pin Wemos

\subsection{Wifi Module ESP8266}

ESP8266 adalah sebuah module wifi (Wireless Fidelity) yang akhir-akhir ini semakin digemari para hardware developer. Selain karena harganya yang sangat terjangkau, module wifi suatu module yang serbaguna, bersifat SOC (System on Chip), sehingga kita bisa melakukan programming langsung ke ESP8266 tanpa memerlukan mikrokontroller tambahan. ESP8266 di kembangkan oleh pengembang asal negeri tiongkok yang bernama "Espressif". Produk seri ESP8266 kini masih terus dalam tahap pengembangan (current R\&D:esp8266-32).

ESP8266 sendiri sudah dilengkapi GPIO (General Purpose Input/Output), dengan adanya GPIO ini kita bisa melakukan fungsi input atau output layaknya sebuah mikrokontroller. Kelebihan lain ESP8266 adalah memilki DEEP SLEEP MODE, sehingga penggunaan daya akan relatif jauh lebih efisien dibandingkan dengan modul wifi.

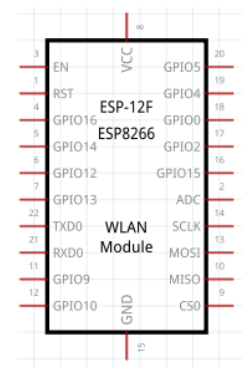

Gambar 2. Wifi ESP8266

\begin{tabular}{|l|c|c|c|c|}
\hline \multicolumn{1}{|c|}{ Description } & Min & Typical & Max & Unit \\
\hline Input Frequency & 2412 & & 2484 & $\mathrm{MB}$ \\
\hline Input impedance & & 50 & & \\
\hline Input reflection & & & -10 & $\mathrm{~dB}$ \\
\hline Ouput Power for 72,2 Mbps & 14 & 15 & 16 & $\mathrm{~dB}$ \\
\hline Ouput Power for 11b mode & 17.5 & 18.5 & 19.5 & $\mathrm{~dB}$ \\
\hline sensitivity & & & & \\
\hline CKK,1 Mbps & & -98 & & $\mathrm{~dB}$ \\
\hline CKK, 1 Mbps & & -98 & & $\mathrm{~dB}$ \\
\hline 6 Mbps (1/2 BPSK) & & -93 & & $\mathrm{~dB}$ \\
\hline 54 Mbps (3/4 64-QAM) & & -76 & & $\mathrm{~dB}$ \\
\hline HT20, MCS7 (65 Mbps, 72,2 Mbps) & & -71 & & $\mathrm{~dB}$ \\
\hline
\end{tabular}

Tabel 1. Spesifikasi ESP8266

\subsection{Sensor DHT22}

Sensor DHT22 merupakan sensor suhu dan kelembaban[11][12][13], yang merupakan produksi Aosong Electronic. Sensor ini terdiri dari dua bagian yaitu sensor kelembaban kapasitif dan thermistor. Sensor DHT22 ini tidak memerlukan rangkaian pengkondisian sinyal dan ADC karena sensor ini menggunakan cip Mikropengendali dengan keluaran sebuah sinyal digital. Komunikasi antar sensor dan rangkaian sistem 
Mikropengendali terjadi melalui komunikasi serial dua arah menggunakan suatu kabel (bidirectional one-wire serial communication). Sensor ini memiliki banyak variasi salah satunya yaitu sensor DHT22 (AM2302). Bentuk fisik dari sensor DHT22 seperti gambar 3.

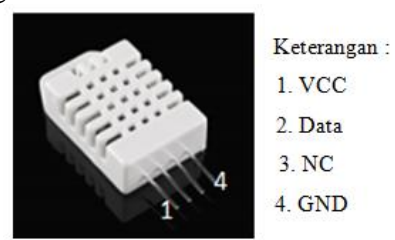

Gambar 3. Sensor DHT22

Adapun spesifikasi teknis dari sensor DHT22 ini yaitu seperti pada tabel 2.

\begin{tabular}{|l|c|}
\hline \multicolumn{1}{|c|}{ Parameter } & Sensor DHT22 \\
\hline Kelas Sensor & Ekonomis \\
\hline Catu Daya & $3-5$ Volt \\
\hline Arus Masukan & $2.5 \mathrm{~mA}(\mathrm{max})$ \\
\hline Rentang Kelembaban & $0-100 \%$ \\
\hline Akurasi Kelembaban & $2-5 \%$ \\
\hline Rentang Suhu & $-40-125^{\circ} \mathrm{C}$ \\
\hline Akurasi Suhu & $\pm 0.5^{\circ} \mathrm{C}$ \\
\hline Kecepatan Pencuplikan & $\leq 0.5 \mathrm{~Hz}$ \\
\hline Dimensi & $15.1 \mathrm{~mm} \times 25 \mathrm{~mm} \times 7.7 \mathrm{~mm}$ \\
\hline
\end{tabular}

Tabel 2. Spesifikasi teknis dari sensor DHT22

\subsection{Transistor Sebagai Switch}

Transistor merupakan komponen elektronik yang mempunyai tiga sambungan. Ketiga sambungan yang terdapat dalam transistor NPN antara lain :

1. Arus kolektor Ic adalah arus yang masuk ke dalam kolektor

2. Arus Basis $\mathrm{I}_{\mathrm{B}}$ adalah arus yang masuk ke dalam basis

3. Arus Emitor $\mathrm{I}_{\mathrm{E}}$ adalah arus yang keluar dari emitor.

4. Voltase Kolektor atau voltase kolektor-emitor, $\mathrm{V}_{\mathrm{CE}}$ adalah voltase antara kolektor dan emitor

5. Voltase Basis atau Voltase basis-emitor, $\mathrm{V}_{\mathrm{BE}}$ adalah voltase antara basis dan emitor.

Salah satu fungsi transistor yaitu berfungsi sebagai saklar. Transistor sebagai saklar adalah dua alat dengan dua sambungan dan mempunyai dua keadaan yaitu on dan off. Keadaan off/cut off/ tutup merupakan keadaan di mana tidak terdapat arus yang mengalir. Sedangkan keadaan On/Saturasi/buka merupakan suatu keadaan di mana arus bisa mengalir dengan bebas atau secara ideal, tidak terdapat resitivitas dan besar voltase pada sakelar sama dengan nol.

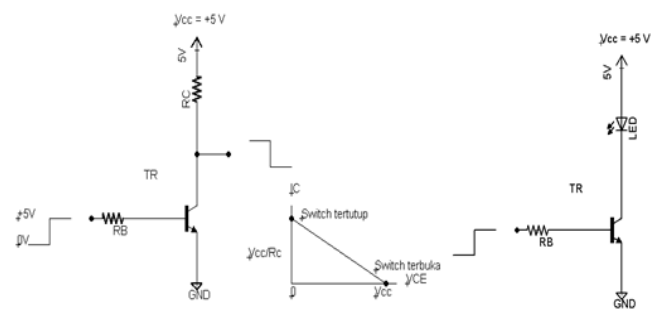

Gambar 4. Rangkaian Saklar Transistor Sebagai Switching Beserta Garis Bebannya

Pada gambar 2.18 Merupakan sebuah contoh rangkaian switching pada transistor. Apabila tegangan masukan rendah atau $L O W$, maka transistor akan tersumbat (cut off). Dalam hal tersebut transistor seperti sebuah sakelar yang terbuka. Namun apabila trgangan tinggi atau $H I G H$, maka transistor akan jenuh atau saturasi dan dioda LED akan menyala. Pada grafik garis beban ,titik teratas merupakan titik jenuh atau saturasi di mana transistor berlaku seperti saklar yang tertutup. Sedangkan titik yang terdapat di bawahnya merupakan titik pancung atau sumbat di mana transistor berlaku seperti saklar terbuka. 
Jika tegangan masukan sebesar $+5 \mathrm{~V}$, maka arus basis didapatkan menggunakan persamaan sebagai berikut

$$
I_{B}=\frac{V_{i}-V_{B E}}{R_{B}}
$$

Apabila transistor diasumsikan terhubung singkat antara kolektor dan emitor, maka idealnya tegangan keluaran jatuh menjadi nol dan arus jenuhnya didapatkan menggunakan persamaan sebagai berikut :

$$
I_{C}=\frac{V_{c c}}{R_{C}}
$$

Arus tersebut kira-kira 10 kali lebih besar dibandingkan arus basis, sehingga cukup mudah untuk menghasilkan kejenuhan yang kuat (hard saturation) pada hampir setiap transistor yang mempunyai sinyal kecil. Hal ini berarti transistor bekerja sebagai suatu switch yang tertutup dan tegangan keluaran Vout mendekati no

\subsection{Aplikasi BLYNK}

Blynk adalah sebuah layanan server yang digunakan untuk mendukung project Internet of Things. Layanan server ini memiliki lingkungan mobile user baik Android maupun iOS. Blynk Aplikasi sebagai pendukung IoT dapat diundung melalui Google play. Blynk mendukung berbagaimacam hardware yang dapat digunakan untuk project Internet of Things. Blynk adalah dashborad digital dengan fasilitas antarmuka grafis dalam pembuatan projectnya. Penambahan komponen pada Blynk Apps dengan cara Drag and Drop sehingga memudahkan dalam penambahan komponen Input/output tanpa perlu kemampuan pemrograman Android maupun iOS.

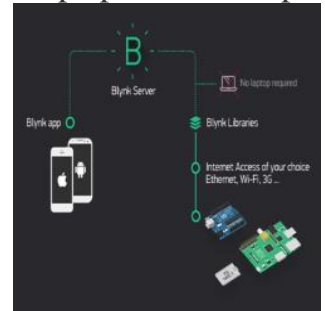

Gambar 5. Blynk Cloud Server

\subsection{Internet dan Intranet}

Internet (Interconnected Networking) adalah hubungan komputer dengan berbagai tipe yang membentuk sistem jaringan yang mencakup seluruh dunia (jaringan komputer global) dengan melalui jalur telekomunikasi seperti telepon, radio link, satelit dan lainnya. Dalam mengatur integrasi dan komunikasi jaringan komputer ini, digunakan protokol yaitu TCP/IP. TCP (Transmission Control Protocol) bertugas memastikan bahwa semua hubungan bekerja dengan benar. Sedangkan IP (Internet Protocol) bertugas mentransmisikan data dari satu komputer ke komputer lain. TCP/IP secara umum berfungsi memilih rute terbaik transmisi data, memilih rute alternatif jika suatu rute tidak dapat di gunakan, mengatur dan mengirimkan paket-paket pengiriman data.

Intranet adalah sebuah jaringan lokal (private network) yang hanya mencakup suatu area tertentu, misalnya dalam suatu area perusahaan, sekolah atau instansi tertentu. Intranet menggunakan protokolprotokol Internet (TCP/IP), untuk membagi informasi rahasia perusahaan atau operasi dalam perusahaan tersebut kepada karyawannya. Kadang- kadang, istilah intranet hanya merujuk kepada layanan yang terlihat, yakni situs web internal perusahaan. Untuk membangun sebuah intranet, maka sebuah jaringan haruslah memiliki beberapa komponen sebagaimana yang digunakan untuk membangun Internet, yakni protokol Internet (Protokol TCP/IP, alamat IP, dan protokol lainnya), client dan juga server. Protokol HTTP dan beberapa protokol Internet lainnya (FTP, POP3, atau SMTP) umumnya merupakan komponen protokol yang sering digunakan. Perbedaan antara internet dan intranet, dari segi jangkauan area, internet menjangkau seluruh dunia, sedangkan intranet terbatas pada area perusahaan atau instansi tertentu. Dari segi cara pemakaian teknologi untuk berkomunikasi, internet menggunakan saluran telekomunikasi sedangkan intranet menggunakan saluran komunikasi dalam perusahaan atau instansi itu sendiri. Sedangkan dari segi pengguna, internet digunakan oleh semua kalangan, intranet hanya digunakan oleh kalangan perusahaan atau instansi tertentu.

\section{Metode Penelitian}

\subsection{Teknik Pengumpulan Data}

Dalam penyusunan makalah metode yang dilakukan dalam pengumpulan data dengan beberapa cara yaitu Observasi, melakukan kajian pustaka, pengumpulan komponen dan module yang dibutuhkan, perancangan, pengujian, pengambilan data, dan ditutup dengan hasil beserta kesimpulan. 


\subsection{Blok Diagram Sistem}
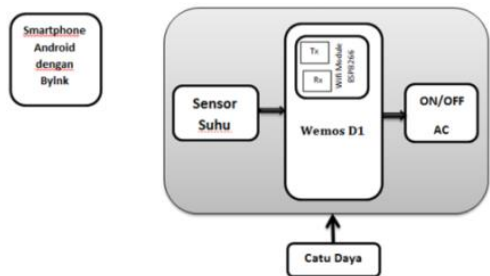

Gambar 6. Blok Diagram Sistem

Fungsi dari tiap blok dalam diagram adalah sebagai berikut :

1. Sensor Suhu DHT22: sensor yang akan membaca keadaan suhu ruangan

2. Wemos : pusat pengolahan data dan kendali perangkat keras yang terhubung dengan Module Wifi ESP8266

3. Module Wifi ESP8266 : merupakan modul transmisi agar perangkat pengendali dapat terhubung dengan aplikasi bylnk dan bertukar infomasi

4. Aplikasi Bylnk : sebagai user interface pengguna untuk pemantauan dan mengirimkan perintah pada perangkat keras.

\subsection{Perancangan Sistem}

Pada perancangan sistem pengiriman data suhu ruangan ini yaitu mikrokontroler dapat membaca suhu ruangan dan apabila suhu ruangan melebihi batas maksimum yaitu di atas $22^{\circ} \mathrm{C}$ maka sistem mikrokontroler akan memberikan perintah ke wifi agar bisa mengirimkan informasi data berupa notifikasi ke smartphone dan smartphone dapat mengirimkan perintah balik untuk menyalakan ac cadangan dengan aplikasi bylnk

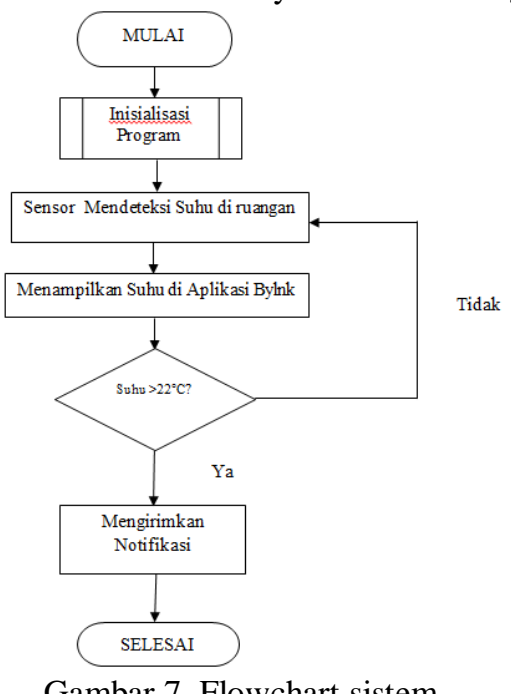

Gambar 7. Flowchart sistem

\subsection{Koneksi WEMOS}

Perangcangan sistem pemantau suhu ini pada sistem mikrokontroler dan transmisi yaitu menggunakan Wemos D1. Wemos D1 mini merupakan sebuah modul wireless yang berbasis mikrokontroler,dimana modul ini selain fungsinya sebagai sistem kendali atau mikrokontroler di dalamnya juga terdapat board wifi ESP266 dimana board tersebut dapat menghubungkan perangkat microcontroller dengan internet via wifi oleh sebab itu digunakannya modul ini karena tidak perlu tambahan board seperti arduino lagi sebagai mikrokontrolernya.

ESP8266 merupakan sebuah chip yang memiliki fitur Wifi dan mendukung stack TCP/IP. Modul kecil ini memungkinkan sebuah mikrokontroler terhubung kedalam jaringan Wifi dan membuat koneksi TCP/IP hanya dengan menggunakan command yang sederhana. Dengan clock $80 \mathrm{MHz}$ chip ini dibekali dengan 4MB 
eksternal RAM serta mendukung format IEEE $802.11 \mathrm{~b} / \mathrm{g} / \mathrm{n}$ dengan kecepatan 54 Mbps per detik dan Frekuensi yang digunakan adalah 2,4 Ghz.

Perancangan pada koneksi wemos ini merupakan bagaimana cara membangun atau menghubungkan wemos dengan koneksi access point untuk terhubung dengan jaringan internet agar bisa saling terhubung dan bertukar data dengan

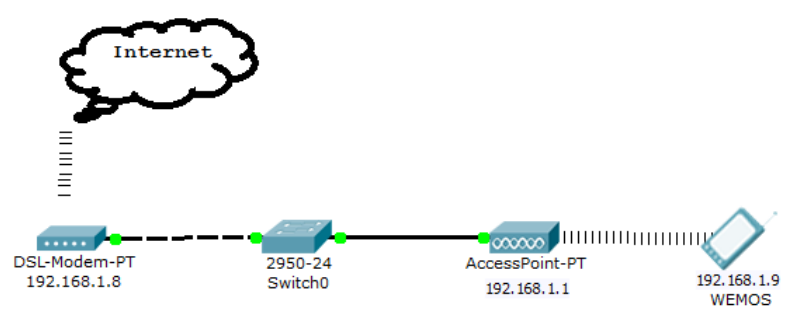

Gambar 8. Arsitektur Jaringan Koneksi Wemos

Setelah terbangunnya arsiterktur jaringan maka akan didapatkan SSID access point yaitu dengan nama "SubangunRio" dan password "konektujuhbelas" maka agar wifi pada wemos dapat terintegrasi dengan access point perangkat wemos terlebih dahulu terhubung dengan IDE Arduino untuk di program. Pada program yang dibuat untuk di upload ke wemos dimasukkan setting wifi pada listing program seperti yang ditunjukkan pada gambar 9. memasukkan SSID aacess point yang dituju yaitu nama dan passwordnya

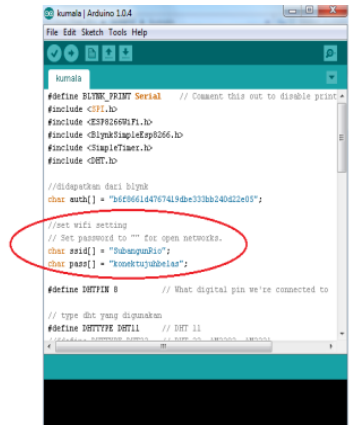

Gambar 9. Program Menghubungkan koneksi dengan wemos

Setelah listing program tersebut di upload ke wemos maka dilakukan pengecekan koneksi apakah wemos sudah berhasil terhubung ke accees point yang dituju. Pengecekan dapat dilakukan pada serial monitor. Selain dari pengecekan di serial monitor untuk membuktikan wemos sudah berhasil terkoneksi dengan internet pada fisik perangkat wemos di bagian wifi terdapat LED yang akan berkedip cepat sebagai tanda wifi sedang terkoneksi dengan jaringan internet atau access point.

\subsection{Perancangan Sistem Kendali}

Perangcangan sistem pemantau suhu ini pada sistem kendali/remote menggunakan samrtphone yang terinstall aplikasi Bylnk untuk penampil nilai suhu dan kendali on/off AC. Pada gambar 10. merupakan hasil tampilan pembuatan dashboard pada bylnk untuk menentukan tombol yang yang akan digunakan sesuai kebutuhan. Setelah dilakukan perancangan pada dashboard maka aplikasi sudah dapat digunakan yaitu untuk menampilkan keadaan suhu secara realtime dan notifikasi pada saat suhu melebihi batas suhu maksimal, selain itu juga terdapat tombol on dan off untuk mengendalikan switch mati dan hidup nya AC. 


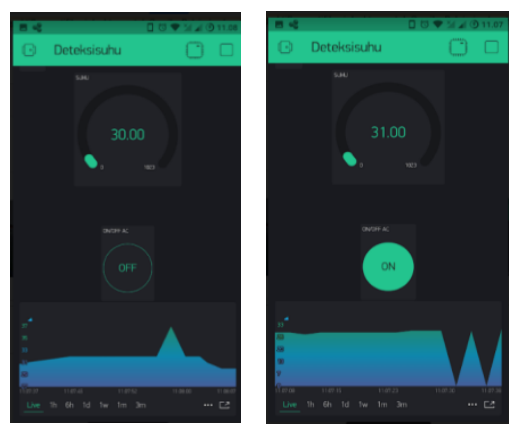

Gambar 10. Perancangan Dashboard Aplikasi Bylnk

Setting modem yang digunakan masih dengan mode PPPoe Client dan Mode DHCP Server dimana IP modem adalah 10.99.50.40 dan pada smartphone sendiri akan mendapatkan IP secara otomatis ketika terkoneksi yaitu menggunakan IP 10.99.50.41. Agar smartphone mendapatkan IP tersebut yaitu hanya dengan menyalakan fitur wifi yang terdapat pada smartphone maka smartphone akan terhubung ke access point yang ada di ruang tersebut kemudian memasukan username dan passrowrd SSID yang dituju yaitu username "Telesandi" dan password "sujarah" maka smartphone akan terkoneksi dengan jaringan yang dituju tersebut seperti yang ditunjukkan pada gambar 11. merupakan koneksi yang didapatkan oleh smartphone.

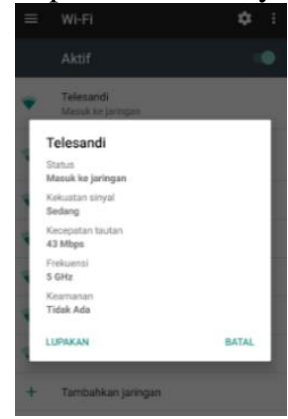

Gambar 11. Koneksi dengan semartphone

\subsection{Perancangan Sistem Kendali}

Sensor suhu pada ruangan perangkat navigasi pesawat udara ini dirancang untuk mendeteksi suhu di ruangan perangkat tersebut. Sensor yang digunakan adalah sensor suhu DHT22 yang bekerja pada tegangan 3 - 5V. Sensor ini memiliki 4 pin yang terdiri dari VCC, Ground, Data, NC (Not Connected). Dengan hanya memiliki 1 pin data, maka sensor DHT22 dapat berkomunikasi dengan controller. Sensor DHT22 ini tidak perlu menggunakan proses ADC karena keluarannya digital. Pada gambar 12 merupakan gambar diagram koneksi pada sensor DHT22.

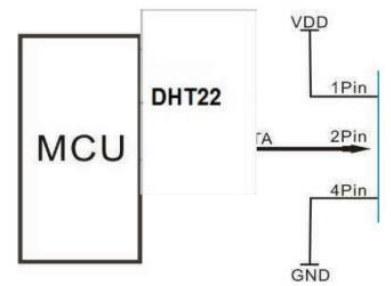

Gambar 12 Diagram Koneksi DHT22

Sensor suhu DHT22 tidak memerlukan proses konversi ADC karena keluarannya adalah digital, namun untuk menghasilkan keluaran digital tersebut DHT22 akan melewati proses pencuplikan dan pengkodean pada sinyal analog yang pertama kali di hasilkan oleh sensor, ADC bekerja dengan cara melakukan sampling atau pencuplikan sinyal pada kecepatan tertentu. Untuk dapat mengeluarkan nilai suhu ruangan maka sensor DHT22 melewati beberapa langkah proses komunikasi sampai dengan sensor tersebut dapat membaca suhu ruangan.

Data single-bus digunakan untuk komunikasi antara MCU dan DHT22 dengan kecepatan 5 ms untuk satu kali komunikasi. Data terdiri dari bagian integral dan desimal, berikut merupakan rumus untuk data. Sensor DHT22 mengirim data bit yang lebih tinggi terlebih dahulu DATA $=8$ bit integral RH data +8 bit decimal RH data +8 bit integral $\mathrm{T}$ data +8 bit decimal $\quad \mathrm{T}$ data + check-sum Jika tranmisi data benar, check-sum harus 8 bit terakhir " 8 bit integral RH data +8 bit decimal $\mathrm{RH}$ data +8 bit integral T data +8 bit decimal T data". 
Ketika MCU mulai mengirim sinyal, DHT22 berubah dari low-power-consumption-mode to runningmode. Ketika MCU selesai mengirim sinyal start alat akan mengirimkan sinyal respon data 40 bit yang mencerminkan kelembapan relatif dan informasi suhu untuk MCU, tanpa sinyal start dari MCU.

Pada gambar 13. Merupakan langkah pertama proses komunikasi MCU mulai mengirim sinyal ke DHT22. Status data bus bebas adalah level tegangan tinggi. Ketika komunikasi antara MCU dan DHT22 mulai, program MCU akan mengubah bentuk level tegangan bus data level tinggi ke level rendah dan proses ini harus di atas minimal $1 \mathrm{~ms}$ untuk memastikan dht bisa mendeteksi sinyal MCU, maka MCU akan menunggu 20-40 ms untuk respon DHT22.

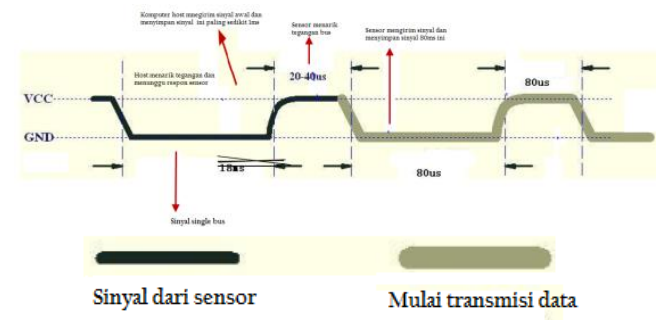

Gambar 13 Proses komunikasi MCU mulai mengirim sinyal ke DHT22

Pada gambar 14. Merupakan langkah kedua proses komunikasi DHT22 mengirim sinyal respon ke MCU. Saat mendeteksi sinyal awal, DHT22 akan mengirimkan sinyal level tegangan rendah dan sinyal ini terakhir 80ms sebagai sinyal respon, maka program DHT22 mengubah tingkat tegangan bus data dari level rendah ke tinggi dan 80ms terakhir persiapan DHT22 untuk mengirimkan data.

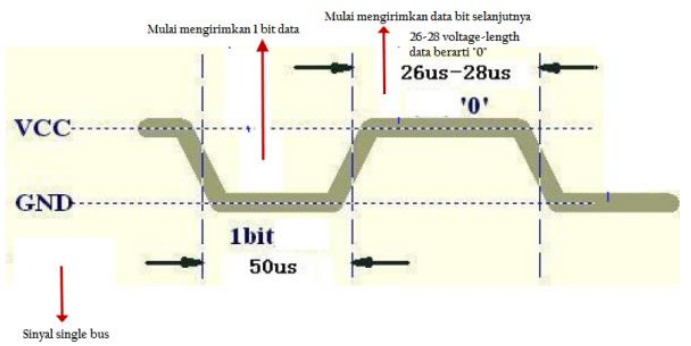

Gambar 14. Proses komunikasi DHT22 mengirim sinyal respon ke MCU

Pada gambar 15. Merupakan langkah ketiga proses komunikasi DHT22 mengirim data ke MCU. Ketika DHT22 mengirim data ke MCU, transmisi setiap bit dimulai dengan level tegangan rendah bertahan 50ms, mengikuti level sinyal tegangan tinggi menentukan bitnya 0 atau 1 .

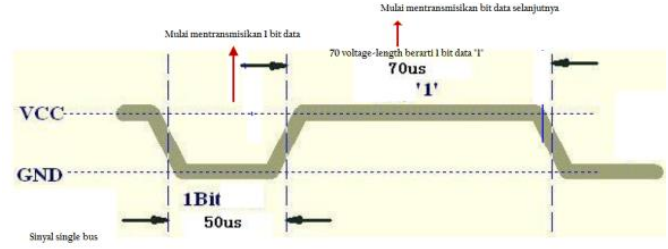

Gambar 15. Proses komunikasi DHT22 mengirim data ke MCU

\section{Hasil dan Pembahasan}

Hasil perancangan alat pedeteksi suhu ruangan dengan aplikasi bylnk ini terdiri dari dua bagian, diantaranya adalah rangkaian perangkat keras dan rangkaian perangkat lunak. Perangkat keras merupakan bagian yang terhubung pada wemos meliputi sensor suhu,switch on/off kipas . Sedangkan bagian perangkat lunak terdiri pembuatan program keseluruhan pada sistem kendali dengan menggunakan IDE Arduino dan perancangan yang dibuat pada dashboard aplikasi bylnk di sisi smartphone.

\subsection{Pengujian Konektivitas Wemos Dengan Access}

Dari gambar 16. Merupakan pengujian konektivitas perangkat wemos dengan access point yang dituju dimana hal tersebut dapat dilihat pengecekannya menggunakan komunikasi serial IDE maka akan muncul connectivity beserta no IP nya menandakan bahwa wemos sudah terkoneksi dengan internet acceess point yang digunakan. 


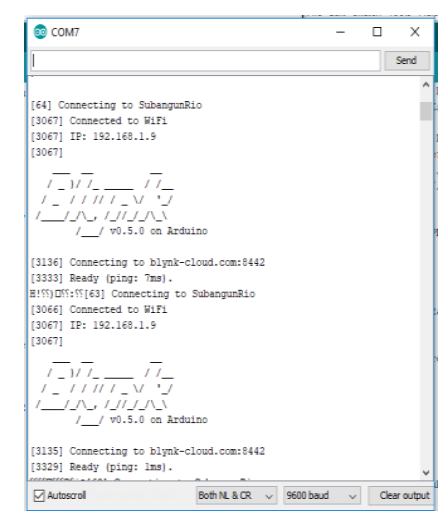

Gambar 16. Konektivitas Wemos

Maka dari pengujian koneksi dapat dilihat bahwa wemos dapat terkoneksi atau terhubung dengan baik ke interne

\subsection{Pengujian Konektivitas Smartphone Dengan Access Poin}

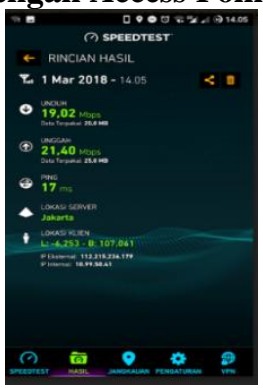

Gambar 17. Hasil Pengujian Tampilan Nilai Suhu dan Notifikasi

Smartpone yang sudah terkoneksi ke access point yang dituju akan mendapatkan no IP secara otomatis dan dapat terkoneksi dengan jaringan internet. Pada gambar 4.2 Merupakan hasil pengujian koneksi smartphone menggunakan speedtest dimana speedtest telah menampilkan hasil ping nya beserta no IP yang didapatkan oleh smartphone yaitu 10.99.50.41. Maka dari pengujian tersebut dapat dilihat bahwa smartphone dapat terkoneksi dengan baik ke jaringan access point yang dituju dengan seperti itu smartphone dapat terhubung ke internet untuk bertukar informasi data ke arah wemos

\subsection{Pengujian Delay}

Pada hasil pengujian delay merupakan pengukuran seberapa lama respon alat dapat beroperasi ketika diberikan sebuah perintah dari aplikasi bylnk, pengukuran mulai dihitung saat perintah berhasil dikirim dari aplikasi bylnk sampai dengan wemos memberikan respon terhadap perintah yang diberikan, data hasil pengukuran delay dapat dilihat pada tabel 4.2 dibawah ini.

\begin{tabular}{|c|c|c|c|}
\hline No & Perintah Terkirim (hh:mm:ss) & Respon Alat (hh:mm:ss) & Delay (hh:mm:ss) \\
\hline 1 & $8: 37: 52$ & $8: 37: 57$ & $0: 00: 05$ \\
\hline 2 & $8: 39: 20$ & $8: 39: 20$ & $0: 00: 00$ \\
\hline 3 & $9: 46: 25$ & $9: 46: 25$ & $0: 00: 00$ \\
\hline 4 & $10: 40: 33$ & $10: 40: 33$ & $0: 00: 00$ \\
\hline 5 & $11: 42: 10$ & $11: 42: 34$ & $0: 00: 24$ \\
\hline 6 & $12: 37: 05$ & $12: 37: 08$ & $0: 00: 03$ \\
\hline 7 & $14: 12: 23$ & $14: 12: 37$ & $0: 00: 14$ \\
\hline 8 & $15: 25: 39$ & $15: 25: 39$ & $0: 00: 00$ \\
\hline 9 & $15: 37: 41$ & $15: 37: 52$ & $0: 00: 11$ \\
\hline 10 & $16: 15: 18$ & $16: 15: 18$ & $0: 00: 00$ \\
\hline \multicolumn{2}{|c|}{ Rata - rata (hh:mm:ss) } \\
\hline
\end{tabular}


Tabel 3. Pengukuran delay

\subsection{Pengujian Sensor Suhu}

Pengujian rerata galat di lakukan pada Sensor DHT22 dengan Thermo-hygrometer analog dengan tujuan untuk mengetahui nilai error suhu yang dihasilkan pada ruangan. Pada pengujian ini perangkat alat pendeteksi suhu ini dinyalakan dan yang sudah terhubung ke smartphone dengan cara mengambil data suhu yang di catat yaitu sebagaimana yang tampil pada aplikasi bylnk pada smartphone. Data hasil pengukuran tersebut nantinya akan di bandingkan dengan hasil pengukuran pada perangkat pengukur suhu Thermo-hygrometer analog. Dengan melakukan sepuluh kali pengambilan sample data pengukuran suhu maka didapatkan data suhu yang terukur yang ditampilkan pada Tabel 4 di bawah ini.

\begin{tabular}{|c|c|c|c|c|c|}
\hline Data ke & Jam & $\begin{array}{c}\text { Sensor DHT22 } \\
\left({ }^{0} \mathrm{C}\right)\end{array}$ & $\begin{array}{c}\text { Thermo-hygrometer Analog } \\
\left({ }^{\circ} \mathrm{C}\right)\end{array}$ & Error & $\begin{array}{c}\text { Nilai } \\
\text { Selisih }\end{array}$ \\
\hline 1 & 10.00 & 29,4 & 31 & $5 \%$ & 1,6 \\
\hline 2 & $10: 01$ & 29,6 & 31 & $5 \%$ & 1,4 \\
\hline 3 & $10: 02$ & 29,5 & 31 & $5 \%$ & 1,5 \\
\hline 4 & $10: 03$ & 29,4 & 31 & $5 \%$ & 1,6 \\
\hline 5 & $10: 04$ & 29,3 & 31 & $5 \%$ & 1,7 \\
\hline 6 & $10: 05$ & 29,3 & 31 & $5 \%$ & 1,7 \\
\hline 7 & $10: 06$ & 29,3 & 31 & $5 \%$ & 1,7 \\
\hline 8 & $10: 07$ & 29,3 & 31 & $5 \%$ & 1,7 \\
\hline 9 & $10: 08$ & 29,3 & 31 & $5 \%$ & 1,7 \\
\hline 10 & $10: 09$ & 29,3 & 31 & $5 \%$ & 1,63 \\
\hline \multicolumn{2}{|c|}{ Rata-rata } & 29,37 & 31 & 0,05 & 1,4 \\
\hline \multicolumn{2}{|c|}{ Minimum } & 29,3 & 31 & 0,05 & 1,7 \\
\hline \multicolumn{2}{|c|}{ Maksimum } & 29,6 & 31 & & $5 \%$ \\
\hline
\end{tabular}

Tabel 4. Pengukuran Suhu

\subsection{Pengujian Fungsi On/Off pada smartphone}

Pada pengujian ini dilakukan untuk mngetahui fungsi tombol on/off untuk menyalan dan mematikan kipas yang ada di sisi perangkat dapat berfungsi dengan baik dan kipas pada sisi perangkat dapat merespon dari kendali yang dijalankan pada smartphone.

Pada saat pengujian kondisi suhu ruangan pada saat yaitu $31^{\circ} \mathrm{C}$ diasumsikan keadaan ruangan pada saat itu adalah $11^{\circ} \mathrm{C}$ yaitu kondisi ruangan perangkat yang tergolong di atas suhu normal. Dapat dillihat pada gmbar 18. ketika suhu melebihi batas suhu maksimal dan tombol ON pada aplikasi di tekan maka LED yang ada di sisi perangkat dapat menyala hal itu berarti tombol ON pada aplikasi dapat berfungsi dengan baik dan switch yang ada pada rangkaian perangkat dapat merespon dan bekerja dengan baik untuk menghidupkan kipas.
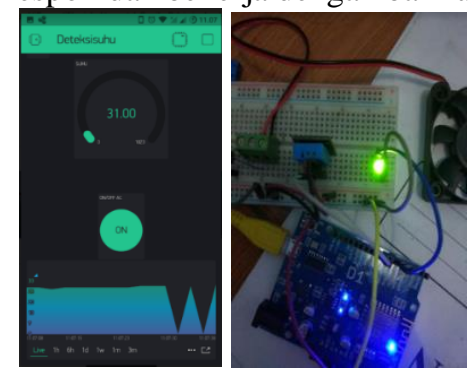

Gambar 18. Kondisi Switch Kipas ON

Kemudian setelah dilakukan pengujian pada tombol ON selanjutnya adalah melaukan pengujian pada tombol OFF untuk mematikan LED diasumsikan suhu pada saat itu kembali normal yaitu $30{ }^{\circ} \mathrm{C}$ atau di ruang perangkat $10^{\circ} \mathrm{C}$ dimana itu merupakan kondisi suhu yang masih normal. Dapat dilihat pada gambar 19. pada saat tombol OFF di tekan pada aplikasi maka lampu yang ada pada sisi perangkat mati itu membuktikan bahwa tombol OFF pada aplikasi dapat berfungsi dengan baik dan switch yang ada pada rangkaian perangkat dapat merespon dan bekerja dengan baik untuk mematikan kipas. 


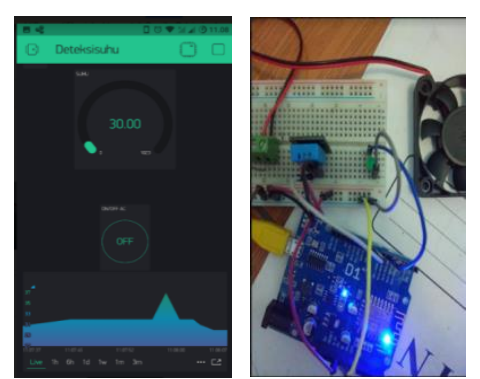

Gambar 19. Kondisi Switch Kipas OFF

\section{Kesimpulan}

Setelah melakukan perancangan terhadap rancang bangun prototype pengendalian jarak jauh pengiriman data suhu ruang perangkat navigasi menggunakan wireless, maka dapat disimpulkan :

1. wemos dapat terkoneksi dengan baik ke jaringan access point yang dituju dengan seperti itu maka wemos dapat terhubung ke internet untuk bertukar informasi ke sisi smartphone

2. Presentase error rate pada sensor suhu DHT22 dibandingkan dengan pengukur sensor Thermohygrometer analog biasa sebesar sebesar $5 \%$.

3. Terdapat selisih nilai pengukuran pada kedua perangkat tersebut yaitu $1.7^{\circ} \mathrm{C}$ menandakan bahwa sensor suhu DHT22. .

\section{Daftar Pustaka}

[1] S. Gifson, A., \& Slamet, "Sistem Pemantau Ruang Jarak jauh dengan Sensor Passive Infrared berbasis Mikrokontroler AT89S52," TELKOMIKA, pp. 201-206, 2009.

[2] T. D. I. Bei, "Universitas 17 Agustus 1945 Jakarta," E-ISSN, J. Kaji. Tek. elektro, vol. 2014, no. April, p. 2014, 2014.

[3] Komala Sari, "Monitoring Transformator Distribusi Bebasis Internet Of Things," 2019.

[4] P. R. Hanif and M. A. Irwansyah, "Prototipe Jam Sholat Qomatron engan Konsep Internet of Things ( IoT ) Menggunakan Wemos D1 Mini Berbasis Web," 2018.

[5] Budioko, "Sistem monitoring suhu jarak jauh berbasis internet of things menggunakan protokol mqtt," 2016.

[6] S. Samsugi and D. Kastutara, "ARDUINO DAN MODUL WIFI ESP8266 SEBAGAI MEDIA KENDALI JARAK JAUH DENGAN ANTARMUKA BERBASIS ANDROID," vol. 12, no. 1, pp. 23 27, 2018.

[7] D. Satria, Z. Zainal, and T. Hidayat, "Plant Watering System Based on the Internet of Thing," J. Nas. Komputasi dan Teknol. Inf., vol. 1, no. 1, 2018.

[8] C. Nanda, W. E. Kurnia, F. T. Industri, F. T. Industri, S. B. Indonesia, and W. Server, "MONITORING SUHU RUANGAN SECARA JARAK JAUH MELALUI ESP8266 Abstrak Seminar Nasional PIMIMD-5 , ITP , Padang," pp. 1-6, 2019.

[9] "Rancang Bangun Smart Home Menggunakan Wemos D1 R2 Arduino Kompatible Berbasis ESP8266 ESP-12F.pdf.".

[10] "Rancang Bangun Kendali Lampu Menggunakan Wemos D1 Mini Dengan Pusat Kendali Media Sosial Telegram.pdf." .

[11] Aosong (Guangzhou) Electronics co, Temperature and Humidity Module. DHT11 Product Manual," Lembar data DHT22. .

[12] W. Adhiwibowo, A. F. Daru, and A. M. Hirzan, "Temperature and Humidity Monitoring Using DHT22 Sensor and Cayenne API," vol. 17, no. 2, pp. 209-214, 2020.

[13] F. Puspasari, T. P. Satya, U. Y. Oktiawati, I. Fahrurrozi, and H. Prisyanti, "Analisis Akurasi Sistem Sensor DHT22 berbasis Arduino terhadap Thermohygrometer Standar,” pp. 1-6, 2020. 